\title{
HUBUNGAN ANTARA POLA ASUH ORANG TUA DENGAN KECENDERUNGAN LOCUS OF CONTROL REMAJA SLTP NEGERI 8 MALALAYANG
}

\author{
${ }^{1}$ Ruth G. R. Beruat \\ ${ }^{2}$ Hendry Opod \\ ${ }^{2}$ Jehosua V. Sinolungan
}

\author{
${ }^{1}$ Kandidat Skripsi Fakultas Kedokteran Universitas Sam Ratulangi Manado \\ ${ }^{2}$ Bagian Psikologi. Fakultas kedokteran Universitas Sam Ratulangi Manado \\ Email: ruthberuat@gmail.com
}

\begin{abstract}
This study aimed to determine a possible link between parenting parents with a predisposition locus of control teens SLTP 8 Manado. The purpose of this paper is to obtain information through empirical data, the relationship of each parenting parents (permissive, authoritharian, authoritative, neglectful) with locus of control teens and get an idea of the locus of control teens SLTP 8 Manado and get an overview of locus of control SLTP 8 Manado. Locus of control is a belief in everyday life. Locus of control one often seen on the way we discript sense of causality that is relatively consistent. Various studies have shown that those who have a tendency internal locus of control are more successful pay attention, more selective towards stimulus, as well as more selective about the task, rather than those who tend to be external, individuals with a tendency external locus of control tend to have confidence. Thus the tendency of individuals with an internal locus of control more have more positive aspects in comparison with the external.
\end{abstract}

Keywords: parents, teenagers, locus of control

\begin{abstract}
Abstrak: Studi ini bertujuan untuk mengetahui kemungkinan adanya hubungan antara pola asuh orang tua dengan kecenderungan locus of control remaja SLTP Negeri 8 Manado. Adapun tujuan dari skripsi ini adalah memperoleh informasi melalui data empirik, mengenai hubungan masing-masing pola asuh orang tua (permissive, authoritharian, authoritative, neglectful) dengan locus of control remaja dan mendapatkan gambaran tentang locus of control remaja SLTP Negeri 8 Manado dan mendapatkan gambaran tentang locus of control SLTP Negeri 8 Manado. Locus of control merupakan keyakinan dalam hidupnya sehari-hari. Locus of control seseorang kerap terlihat dari caranya mengekspersikan sense of causality yang relative konsisten. Berbagai penelitian membuktikan bahwa mereka yang memiliki kecenderungan locus of control internal lebih berhasil mengarahklan perhatiannya,lebih selektif terhadap stimukus, serta lebih selektif terhadap tugas, daripada mereka yang cenderung eksternal, individu-individu dengan kecenderungan locus of control eksternal cenderung memiliki rasa percaya diri. Dengan demikian individu-individu dengan kecenderungan locus of control internal lebih banyak memiliki aspek yang lebih positif di bandingkan dengan eksternal.
\end{abstract}

Kata kunci: orang tua, remaja, locus of control

Salah satu periode dalam rentan kehidupan individu adalah masa remaja. Fase ini merupakan segmen kehidupan yang penting dalam siklus perkembangan individu, dan merupakan masa transisi yang dapat diarahkan kepada 
perkembangan masa dewasa yang sehat. ${ }^{2}$ Masa remaja atau "endolescence" berasal dari bahasa latin "adolescere" yang berarti "tumbuh" atau "tumbuh menjadi dewasa". Apabila diartikan dalam konteks yang lebih luas, akan mencangkup kematangan mental, emosional, sosial dan fisik. ${ }^{5}$ Selanjutnya ada ahli psikologi membatasi masa remaja yang berkisar dari usia 12 sampai dengan 24 tahun. Pada masa remaja ini individu mencapai pertumbuhan fisik yang maksimal, dan pada masa ini pula tercapai kematangan kemampuan reproduksi. Kematangan ini menyebabkan remaja mempunyai perhatian terhadap lawan jenisnya, dan remaja akan berubah untuk memikat lawan jenis tersebut. ${ }^{5}$ selain pertumbuhan fisik, pada masa ini akan terjadi juga perkembangan fungsi-fungsi psikologis yang ditandai dengan peningkatan kekuatan mental, kemampuan berpikir, kemampuan dalam memahami, dan kemampuan dalam mengingat. Dengan adanya peningkatan dalam kemampuan mentakl tersebut maka remaja mempunyai perhatian terhadap lingkungan sosial dan intelektual. 5,6 Dengan memperhatikan pengertian remaja yang dikemukakan di atas, dapat disimpulkan bahwa masa remaja merupakan suatu fase pertumbuhan dari anak yang belum matang menuju orang dewasa yang matang; suatu periode transisi secara biologis, psikologis, dan social.

Seorang ahli psikologi mengajukan suatu pendapat, bahwa setiap orang memiliki locus of control. Locus of control merupakan keyakinan (belief) terhadap sumber-sumber yang mengontrol kejadiankejadian dalam hidupnya sehari-hari. ${ }^{3}$ Sementara yang lain menyebut locus of control sebagai salah satu sub aspek kepribadian yang terlibat dalam proses penilaian (judgemental process) sebelum individu melakukan suatu respons. ${ }^{7}$ Demikian juga pendapat lainnya mengemukakan bahwa locus of control merupakan suatu harapan yang digeneralisasikan mengenai hubungan antara usaha dan ketrampilan dengan kesuksesan secara objektif. ${ }^{8}$
Pada beberapa tahun terakhir ini, banyak pemberitaan tentang aktivitas remaja yang berkonotasi negatif. Karena itu langkah-langkah untuk meminimalisir, mencegah dan mengulangi masalah remaja tersebut telah dicoba untuk memasyarakatkan. Slah satunya adalah upaya menyadarkan masyarakat mengenai pentingnya peran orang tua dalam membesarkan,membina, dan membidik remaja.

Berperan sebagai orang tua, berarti memiliki kewajiban untuk sebaik mungkin mengusahakan agar remaja menjadi individu yang sesuai dengan harapan orang tua. Oleh karena itu melalui pola asuh orang tua menanamkan standar nilai memperkuat sikap serta tingkah laku yang dianggap positif dan memperoileh sikap dan tingkah laku yang dianggap negative, serta memberikan bimbingan atau pengarahan agar remaja mampu melakukan banyak hal demi kemandiriannya. ${ }^{1}$

Melalui strategi tersebut orang tua menmgharapkan agar remaja mampu menilai mana yang pantas dilakukan dan mana yang tidak pantas dilakukan, mampu merencanakan mas depannya, dapat mengembangkan diri, dan memiliki kesanggupan untuk mencapai apa yang ingin dicapai dalam hidupnya, sehingga remaja tidak akan mengalami kesulitan yang berarti ketika memasuki masa dewasa. ${ }^{1,2}$

Pada masa sekarang ini tugas orang tua dalam konteks pengasuhan tidaklah mudah. Arus informasi yang terbuka dan cepat dapat menyampaikan berbagai macam masukan bagi remaja. Mulai dari masukanh yang sesuai dengan apa yang telah dianjurkan oleh orang tua sampai dengan masukan yang sama sekali bertolak belakang dengan pandangan ideal orang tua. Masukan-masukan ini dapat mempengaruhi remaja, sehingga tujuan orang tua untuk membentuk remaja “ideal”dapat terlambat. Pengaruh lain yang dapat menjadi tandingan bagi orang tua adalah pengaruh dari teman sebaya, karena pada masa remaja ini, individu cenderung lebih berorientasi kepada teman sebayanya 
dibandingkan kepada orang tuanya sendiri. Kerangka penilaian banyak diarahkan oleh pendapat teman. Jika menurut teman suatu hal itu baik atau pantas dilakukan oleh individu seusia mereka, maka hal itu bcendrung dituruti dan dilakukan oleh teman-teman lainnya. ${ }^{2}$

Suatu fenomena mengenai kuatnya pengaruh dari teman sebaya dapat di simak dal suatu laporan yang diturunkan pada harian surat kabar Media Reformasi, edisi 161 tahun 2012, Menurut laporan tersebut, saat ini sering dijumpai remaja melakukan aktivitas yang kurang bermanfaat seperti mejeng di pusat perbelanjaan, di pusat hiburan ata fast food, mabal pada jam sekolah, ikut tawuran, dan ada yang menggunakan NAZA (narkotika, alkohol, dan zat adiktif). Menurut pengakuan daribeberapa remaja yang melakukan aktivitas tersebut, pada awalnya mereka hanya mengikuti ajakan teman. Namun kemudian mereka menikmatinya dan akhirnya menjadi terbiasa.

Menanggapi hal itu tentu saja orang tua tidak dapat mencampuri aktivitas remaja dengan remaja sebanyanya secara penuh. Yang dapat dilakukan oleh orang tua adalah mengupayakan cara pengasuhan yang tepat bagi remaja, agar remaja memiliki "bekal" untuk melakukan sosialisasi di luar rumah. Dengan demikian meskipun jauh dari pengawasan tua, remaja akan mampu bertanggung jawab.

\section{METODE PENELITIAN}

Penelitian ini dilakukan dengan menggunakan rancangan penelitian korelasional. Penelitian dilakukan di SLTP Negeri 8 Manado, selama bulan OktoberDesember 2012. Populasi adalah siswa SLTP Negeri 8 Manado, tahun ajaran 2012/2013. Karateristik populasi yang diperhatikan adalah : - berusia 13-16 tahun, - kelas II, tinggal dengan orang tua.

\section{HASIL PENELITIAN}

Dalam penelitian ini dirumuskan beberapa hipotesis penelitian sebagai berikut :
1. Terdapat hubungan yang berarati antara pola asuh permissive dengan kecenderungan locus of control remaja

2. Terdapat hubungan yang berarti antara pola asuh authoritative dengan kecenderungan locus of control remaja

3. Terdapat hubungan yang berarti antara pola asuh authoritarian dengan kecenderungan locus of control remaja

4. Terdapat hubungan yang berarti antara pola asuh neglectful dengan kecenderungan locus of control remaja

Table 1.1. Prosentase Kecenderungan Locus of Control Remaja pada Masing-masing Pola Asuh Orang Tua.

\begin{tabular}{lllllll}
\hline \multirow{3}{*}{ Pola Asuh } & \multicolumn{4}{c}{ Locus Of Control } & \multicolumn{2}{c}{ Total } \\
\cline { 2 - 5 } & Internal & \multicolumn{2}{c}{ Ekternal } & \multicolumn{2}{c}{ Total } \\
\cline { 2 - 5 } & $\mathbf{F}$ & $\mathbf{\%}$ & $\mathbf{F}$ & $\mathbf{\%}$ & F & $\mathbf{\%}$ \\
\hline Permissive & 9 & 32,14 & 19 & 67,86 & 28 & 100 \\
\hline Authoritative & 26 & 60,53 & 17 & 39,47 & 43 & 100 \\
\hline Authoritarian & 6 & 31,57 & 13 & 68,42 & 19 & 100 \\
\hline Neglectful & 10 & 37,03 & 17 & 62,96 & 27 & 100 \\
\hline Jumlah & 51 & 43,58 & 66 & 56,41 & 117 & 100 \\
\hline
\end{tabular}

Berdasarkan Tabel di atas dapat dilihat bahwa,

- Kecenderungan locus of control remaja dari pola asuh permissive adalah eksternal $(67,86 \%)$

- Kecenderungan locus of control remaja dari pola asuh Authoritative adalah Internal $(60,53 \%)$

- Kecenderungan locus of control remaja dari pola asuh Authoritarian adalah eksternal $(68,42 \%)$

- Kecenderungan locus of control remaja dari pola asuh Neglectful adalah eksternal $(62,96 \%)$

\section{BAHASAN}

Berdasarkan hasil penelitian diperoleh fakta bahwa orang tua yang permissive tidak mendukung pertkembangan locus of control. Hal ini dapat terjadi karena orang tua yang permissive dalam praktek asuhannya kurang menuntut dan kurang mnengharapkan tingkah laku yang matang dan tanggung jawab remaja. Oleh karena itu orang tua jarang memberikan hukuman 
ataupun nasehat apabila remaja melakukan yang tidak sesuai dengan standar orang tua. Dari hasil penelitian diperoleh bahwa pola asuh Authoritative mendukung pengembangan locus of control remaja. Mengapa, sebab orang tua yang authoritative menerapkan kontrol ketat, menerapkan tuntutan yang jelas, mengarahkan remaja secara jelas, konsisten dan rasional. Dengan perlakuan demikian remaja akan memiliki panduan untuk bertingkah laku tanpa harus merasa rasional. Tuntutan yang jelas dan konsistensi kontrol akan membuat remaja yakin dengan apa yang harus dilakukannya agar memperoleh reinforcement yang diingini. Pengalaman-pengalaman ini akang terakumulasi dan akan digeneralisasikan sehingga terbentuk suatu keyakinan bahwa remaja tersebut dapat mengedalikan hidupnya. Reamaj yang memiliki keyakinan demikian akan dapat mengatasi tuntutan maupun tekanan dari lingkungan.

Untuk pola asuh Authoritarian diperoleh data bahwa pola asuh ini tidak mendukung pengembangan locus of control remaja. Hal ini dapat dijelaskan karena orang tua authoritarian memiliki tuntutan yang tinggi terhadap remaja. Orang tua menerapkan kontrol yang ketat serta mengevaluasi tingkah laku remaja berdasarkan standar mutlak yang ditetapkan sendiri oleh orang tua. Dalam praktek sehari-hari orang tua memebrikan hukuman / reinforcement negative bagi setiap tingkah laku yang tidak sesuai sengan aturan orang tua. Contoh dari fakta tersebut dalam penelitian ini $89,10 \%$ orang tua authoritarian selalu memberikan teguran keras apabila remaja tidak langsung pulang sesuai sekolah. Reinforcement negative yang diberikan oleh orang tua tidak diimbangi dengan reinforcement positif bagi tingkah laku yang sesuai dengan standar orang tua. Hal iniu dapat terlihat dari data bahwa $78,50 \%$ orang tya authoritarian selalu tidak memberikan pujian atau penghargaan apabila remaja berhasil melaksanakan tugas yang orang tua berikan. $75,40 \%$ orang tua authoritarian tidak pernah menunjukkan penghargaan bagaimanapun hasil yang telah remaja usahakan. Oleh karena itu perlakuan orang tua tidak berimbang dalam menanggapi tingkah laku posistif dengan tingkah laku negatif remaja, maka remaja akan mempresepsikan bahwa reinforcement yang ia peroleh tidak sepenuhnya bergantung pada tingkah laku atau prestasi. Dengan persepsi demikian, harapan akan berhasil dalam mengupayakan reinforcement yang ia inginkan akan menurun.

Menurut hasil penelitian, pola asuh neglectful yang ditandai dengan penerapan kontrol dan kehangatan dalam intensitas yang rendah, ternyata mendukung pengemabangan locus of control remaja. Berdasarkan proporsi kecenderungan locus of control pada table 4.5 tampak bahwa $62,98 \%$ remaja yang diasuh secara neglectful memiliki kecenderungan locus of control eksternal.dan 37,03\% remaja memiliki kecenderungan locus of control internal. Hal ini berarti pola asuh neglectful lebih memberikan pengaruh dalam pengembangan kecenderungan locus of control kea rah eksternal.

\section{SIMPULAN}

Berdasarkan hasil pengujian hipotesis dan pembahasan hasil penelitian, maka dapat disimpulkan bahwa hubungan antara pola asuh orang tua dengan kecenderungan locus of control remaja sebagai berikut : Kontrol yang dipadukan dengan kehangatan dalam intensitas yang tinggi akan mengembangkan locus of control remaja kearah internal, sedangkan kontrol yang dipadukan dengan kehangatan dalam intensitas yang rendah akan mengembangakn locus of control remaja kearah eksternal.

\section{DAFTAR PUSTAKA}

1. Berk JE. Child Development. New York: Allyn and Bacoon, Inc, 2001.

2. Hurlock EB. Adolescence Development. 4 th Edition. New York: Mc.Graw Hill, Inc, 2003. 
3. Maccoby EE. Social Development: Child Relationship. New York: Harcourt Brace Jovanovich Publisher, 2000.

4. Rotter JB, June EC, Jerry EP. Applications of Social Learning Theory of Personallity. 4 th Edition. New York: Holt, Rinehart and Winston, Inc, 2002.

5. Lefdcourt HM. Locus of Control : Current psychological Growth and ParentTrends in theory and research. $2^{\text {nd }}$ Edition. New Jersey: Lawrence Erlbaum Associates Publishers, 2002.

6. Berzonsky MND. Adolescent Development. New York: Macmillan Publishing Co. Inc, 2001.

7. Baurmrind D. Authoritarian vs Authoritative Parental control. Journal of adolescene. 2000. 